Research, Society and Development, v. 10, n. 14, e08101421904, 2021

(CC BY 4.0) | ISSN 2525-3409 | DOI: http://dx.doi.org/10.33448/rsd-v10i14.21904

\title{
Desenvolvimento e controle de qualidade de formulação Anti-Age com óleo de Vitis sp.
}

\author{
Development and quality control of Anti-Age base with oil from Vitis $s p$. \\ Desarrollo y control de calidad de la base Anti-Age con aceite de Vitis sp.
}

Recebido: 16/10/2021 | Revisado: 20/10/2021 | Aceito: 21/10/2021 | Publicado: 23/10/2021

\author{
Luzimar Costa Ramos \\ ORCID: https://orcid.org/0000-0001-9822-6670 \\ Universidade Nilton Lins, Brasil \\ E-mail: luzimar-gym@hotmail.com \\ Triciane Lyandra Coelho de Lima \\ ORCID: https://orcid.org/0000-0002-5392-9775 \\ Artesâ Farmácia de manipulação, Brasil \\ E-mail: lyandracoelho.1@gmail.com \\ Gabriel Oliveira De Souza \\ ORCID: https://orcid.org/0000-0001-9168-074X \\ Universidade Nilton Lins, Brasil \\ E-mail: gabriel.souza@uniniltonlins.edu.br
}

\begin{abstract}
Resumo
O potencial fitocosméticos de ativos naturais provenientes da flora brasileira frente ao mercado farmacêutico é inquestionável. Grandes empresas estão sempre em busca de novos ativos e formulações que possam propiciar a seus clientes cuidados para o combate do envelhecimento e o reparo de danos causados pela senescência. Nesse contexto de inovação, o objetivo desta pesquisa foi a produção de uma formulação anti-age contendo óleo de Vitis sp. e avaliar sua estabilidade preliminar. O óleo foi obtido de fornecedor certificado, afim de garantir a qualidade do produto para fins cosméticos. Posteriormente seguiu-se o preparo das amostras na concentração de $1 \% .3 \%$ e $5 \%$ de óleo na formulação O/A. Seguiu-se com base nos manuais nacionais de boas práticas de produção de cosméticos as análises organolépticas, $\mathrm{pH}$, densidade, estresse térmico e centrifugação. Todas as análises foram realizadas em triplicata nos dias $1 \mathrm{e} 12$ do teste. As formulações foram estáveis ao estresse térmico e ao teste de centrifugação. Em relação a densidade apresentaram valores finais de $1,46 \mathrm{gml}^{-1} \pm 0,12,1,48 \mathrm{gml}^{-1} \pm 0,01 \mathrm{e} 1,49 \mathrm{gml}^{-1} \pm 0,15$ respectivamente para as formulações de $1 \%, 3 \%$ e $5 \%$. Outra analise realizada foi a de $\mathrm{pH}$ onde foram encontrados resultados de $4,55 \pm 0,01$, $4,56 \pm 0,14,4,58 \pm 0,16$ respectivamente para as formulações de $1 \%, 3 \%$ e $5 \%$. Os valores das análises sugerem uma formulação que foi estável frente o estresse térmico e avaliação preliminar da estabilidade que tem justamente função de acelerar qualquer processo de instabilidade das formulações. Dessa forma a formulação O/A elaborada é um produto interessante a ser produzido, devido a sua simplicidade. O que favorece uma possível segunda etapa dessa pesquisa, como a ampliação das avaliações de estabilidade e físico-químicas, avaliação microbiológica e investigação das atividades terapêuticas. Apesar da literatura dispor de informações sobre as atividades biológicas da Vitis sp, testes para investigação de atividades biológicas da formulação e perfil químico precisam ser feitos para maiores aprofundamentos do tema.
\end{abstract}

Palavras-chave: Anti-age; Formulação; Estabilidade.

\begin{abstract}
The phytocosmetics potential of natural actives from the Brazilian flora against the pharmaceutical market is unquestionable. Large companies are always looking for new actives and formulations that can provide their customers with care to fight aging and repair damage caused by senescence. In this context of innovation, the objective of this research was the production of an anti-age formulation containing oil from Vitis sp. and assess its preliminary stability. The oil was obtained from a certified supplier, in order to guarantee the quality of the products for cosmetic purposes. Subsequently, samples were prepared at a concentration of $1 \% .3 \%$ and $5 \%$ oil in the $\mathrm{O} / \mathrm{W}$ formulation. Based on the national manuals of good cosmetic production practices, organoleptic, $\mathrm{pH}$, density, thermal stress and centrifugation analyses were followed. All analyzes were performed in triplicate on days 1 and 12 of the test. The formulations were stable to thermal stress and to the centrifugation test. Regarding density, they presented final values of 1.46 gml-1 \pm $0.12,1.48$ gml- $1 \pm 0.01$ and 1.49 gml- $1 \pm 0.15$ respectively for the formulations of $1 \%, 3 \%$ and $5 \%$. Another analysis performed was the $\mathrm{pH}$ where results were found of $4.55 \pm 0.01,4.56 \pm 0.14,4.58 \pm 0.16$ respectively for the formulations of $1 \%, 3 \%$ and $5 \%$. The analysis values suggest a formulation that was stable under thermal stress and a preliminary stability evaluation that has the function of accelerating any instability process of the formulations. Thus, the O/W formulation elaborated is an interesting product to be produced, due to its simplicity. This favors a possible second stage of this research, such as the expansion of stability and physicochemical assessments, microbiological assessment and investigation of therapeutic activities. Although the literature has information on the biological activities of Vitis $s p$,
\end{abstract}


Research, Society and Development, v. 10, n. 14, e08101421904, 2021

(CC BY 4.0) | ISSN 2525-3409 | DOI: http://dx.doi.org/10.33448/rsd-v10i14.21904

tests to investigate the biological activities of the formulation and chemical profile need to be carried out to further deepen the topic.

Keywords: Anti-age; Formulation; Stability.

\section{Resumen}

El potencial fitocosmético de los activos naturales de la flora brasileña frente al mercado farmacéutico es incuestionable. Las grandes empresas siempre buscan nuevos activos y formulaciones que puedan brindar a sus clientes cuidados para combatir el envejecimiento y reparar los daños causados por la senescencia. En este contexto de innovación, el objetivo de esta investigación fue la producción de una formulación anti-age que contenga aceite de Vitis sp. y evaluar su estabilidad preliminar. El aceite se obtuvo de un proveedor certificado para garantizar la calidad de los productos con fines cosméticos. Posteriormente, se prepararon muestras a una concentración del $1 \%$. 3\% y $5 \%$ de aceite en la formulación $\mathrm{O} / \mathrm{W}$. Con base en los manuales nacionales de buenas prácticas de producción de cosméticos, se siguieron análisis organolépticos, de $\mathrm{pH}$, densidad, estrés térmico y centrifugación. Todos los análisis se realizaron por triplicado los días 1 y 12 de la prueba. Las formulaciones fueron estables al estrés térmico y al ensayo de centrifugación. En cuanto a la densidad, presentaron valores finales de 1.46 gml- $1 \pm 0.12,1.48$ gml- $1 \pm 0.01$ y 1.49 gml- $1 \pm 0.15$ respectivamente para las formulaciones de $1 \%, 3 \%$ y $5 \%$. Otro análisis realizado fue el $\mathrm{pH}$ donde se encontraron resultados de $4.55 \pm$ $0.01,4.56 \pm 0.14,4.58 \pm 0.16$ respectivamente para las formulaciones de $1 \%, 3 \%$ y $5 \%$. Los valores de análisis sugieren una formulación estable bajo estrés térmico y una evaluación preliminar de estabilidad que tiene la función de acelerar cualquier proceso de inestabilidad de las formulaciones. Así, la formulación $\mathrm{O} / \mathrm{W}$ elaborada es un producto interesante a producir, debido a su sencillez. Esto favorece una posible segunda etapa de esta investigación, como la expansión de las evaluaciones de estabilidad y fisicoquímicas, la evaluación microbiológica y la investigación de actividades terapéuticas. Aunque la literatura tiene información sobre las actividades biológicas de Vitis sp, es necesario realizar pruebas para investigar las actividades biológicas de la formulación y el perfil químico para profundizar aún más el tema.

Palabras clave: Anti-edad; Formulación; Estabilidad.

\section{Introdução}

O envelhecimento é um processo fisiológico gradativo, onde a luta contra o relógio da vida torna-se constante. Assim, buscamos por formulações que proporcionam o rejuvenescimento ou que retardem o envelhecimento. As substâncias antioxidantes que atuam contra radicais livres minimizando esse processo de envelhecimento tem sido a saída encontrada para minimizar o impacto do tempo (Epamig, 2007).

O Brasil é um dos maiores consumidores de cosméticos e serviços de beleza do mundo (Moraes et. al, 2019). Esse panorama incentiva, o crescimento da indústria nacional de cosméticos e da demanda por formulações inovadoras. Segundo a RDC 07/15 da Agência Nacional de Vigilância Sanitária (ANVISA), cosméticos são misturas de uso externo que podem ser aplicadas em diversas partes do corpo com a finalidade de perfumar, modificar aspecto e cheiro, limpar e manter em bom estado. Os cremes são os cosméticos mais usados e estão inclusos na classificação como produtos de grau 1, por possuírem propriedades básicas e não requerer instruções ao uso.

Os radicais livres são moléculas altamente reativas que são produtos do metabolismo celular, onde na sua maioria são derivados do diatômico $\left(\mathrm{O}_{2}\right)$, e por esses motivos são chamados de espécies reativas de oxigênio (Rodrigues et. al., 2021). Por muitos anos as plantas tem sido fonte de estruturas complexas, diversas e biologicamente ativas, que tem sido importantes protagonistas do combate do envelhecimento (Atasanov et al., 2015). De 1981 a 2014, 50\% dos produtos aprovados são oriundos direto ou indiretamente de plantas medicinais ou outro tipo de plantas (Newman, 2016).

As uvas são frutos com funções diversas como, por exemplo, utilizadas para produzir vinho, suco, doce, passas, vinagres e também consumidas naturalmente (Oliveira, 2010). Esses frutos possuem em sua composição flavonoides, ácidos fenólicos e taninos, utilizados para impedir os danos oxidativos nos tecidos e inibindo a produção de radicais livres, e consequentemente o envelhecimento (Rodrigues et. al., 2021).

Possuindo propriedades umectantes, o óleo da semente da uva mantém a pele hidratada prevenindo a descamação, além de ser rico em vitamina E (Tocoferol), o que ajuda na prevenção de rugas, estrias, cicatrizes, e o envelhecimento precoce. Possui também um elevado teor de ácido linoleico (Amaral et. al., 2019). 
Research, Society and Development, v. 10, n. 14, e08101421904, 2021

(CC BY 4.0) | ISSN 2525-3409 | DOI: http://dx.doi.org/10.33448/rsd-v10i14.21904

Os cremes hidratantes são os cosméticos mais importantes, pois possuem ação preventiva contra principalmente o envelhecimento precoce. Os ativos presentes nos cremes são responsáveis pelo mecanismo de ação dessas formas farmacêuticas. Os ativos de importância cosmética mais comum são o colágeno, ácido hialurônico, glicerina, ureia e óleos essenciais (Rodrigues et. al., 1995).

Com base nas propriedades farmacológicas descritas acerca do uso de óleo de Vitis sp., esta pesquisa teve como objetivo desenvolver uma formulação a base de óleo de Vitis sp. e realizar uma avaliação preliminar dessa formulação.

\section{Metodologia}

\subsection{Amostragem}

O óleo de Vitis sp. foi obtido de fornecedores do Rio de Janeiro com certificados de controle de qualidade que garantiam a integridade do produto para seu uso com cosmético.

\subsection{Desenvolvimento da formulação}

A formulação da base consistiu em emulsão do tipo O/A de acordo com o Formulário Nacional (2012), representado no Quadro 1, preparada 24 horas antes do uso. A emulsão foi preparada aquecendo as fases 1 e 2 a $75^{\circ} \mathrm{C}$, separadamente. Logo após, verteu-se a fase 2 sobre a fase 1 , sob agitação constante e homogeneização à temperatura inferior a $40^{\circ} \mathrm{C}$. A formulação (300g) foi armazenada em recipiente de plástico hermeticamente fechado, ao abrigo da luz até utilização.

Quadro 1: Composição da formulação padrão, em percentual por peso.

\begin{tabular}{|c|c|c|}
\hline \multicolumn{2}{|c|}{ Fase oleosa (1) } & \% \\
\hline Componente & Função & 5 \\
\hline Cera Polawax & Emulsificante & 4 \\
\hline Óleo mineral & Emoliente & 3 \\
\hline Oleato de Decila & Emoliente & 5 \\
\hline Triglicerídeos de ácido cáprico e caprílico & Emoliente \\
\hline Parafina liquída & Agente de consistência & 0,01 \\
\hline EDTA & Quelante & \% \\
\hline Componente & Função & 0,05 \\
\hline Putilhidroxitolueno (BHT) aquosa (2) & Antioxidante \\
\hline Propilenoglicol & Emoliente & 0,15 \\
\hline Nipazim & Conservante & 0,10 \\
\hline Água destilada & Conservante & q.s.p. 50 \\
\hline
\end{tabular}

Fonte: Autores (2021).

Após a preparação da base, incorporou três diferentes concentrações de óleo de Vitis sp. em três partes de creme base, $1 \%, 3 \%$ e $5 \%$. Os cremes de diferentes concentrações foram submetidos em triplicata a análises físico-químicas de estabilidade acelerada de acordo com Brasil, 2004 representados na Figura 1. 


\subsection{Avaliação físico-química}

\subsubsection{Avaliação macroscópica}

As características organolépticas e a homogeneidade das amostras foram observadas após 24 horas de preparo (Brasil, 2004) representados no Quadro 2.

\subsubsection{Determinação do valor do $\mathrm{pH}$}

Os cremes de diferentes concentrações foram diluídos em água destilada e a $25^{\circ} \mathrm{C}$ mensurou o pH com o auxílio do pHmetro digital, mediu-se o pH no dia 1, dia em que os cremes foram preparados, e no dia 12, após o estresse térmico (Brasil, 2004) representados na Tabela 2.

\subsubsection{Determinação da densidade}

Os cremes produzidos foram pesados e colocados em uma proveta, determinando os volumes e com os valores obtidos, calculou-se a densidade (Brasil, 2004) representados na Tabela 3.

\subsection{Avaliação de estabilidade acelerada}

\subsubsection{Teste de centrifugação}

Depois da avaliação macroscópica, das formulações foram separados $5 \mathrm{~g}$ e submetidos a centrifugação a $6000 \mathrm{rpm}$ por 5 minutos e por fim, realizou-se as leituras dos resultados, verificar se houve quebra de fases (Brasil, 2004) representados nas Figuras 4A e 4B.

\subsubsection{Estresse térmico}

Separou-se as emulsões em tubos de ensaio, selando e submetendo parte à temperatura variável de $45^{\circ} \mathrm{C} \pm 2^{\circ} \mathrm{C}$ e a outra à temperatura ambiente (controle). As leituras foram realizadas no início do teste e após o dia 12. (Brasil, 2004) representados Figura 4A e 4B. 
Figura 1: Fluxograma da metodologia empregada na pesquisa.
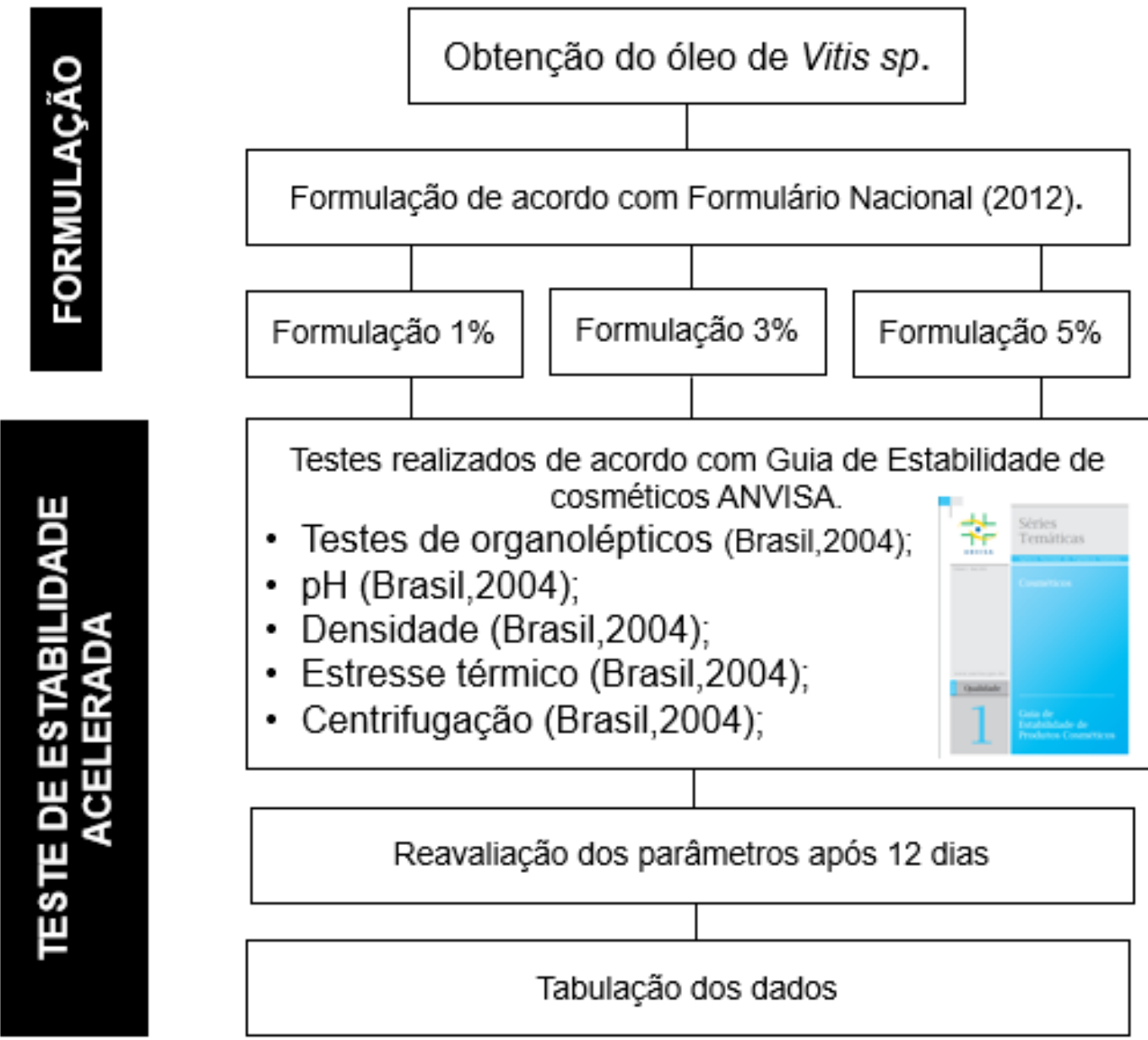

Fonte: Autores (2021).

\section{Resultados e Discussões}

A escolha da formulação foi realizada de acordo com formulário nacional da ANVISA, analisando cada excipiente e concentração na formulação (Quadro 1), para que depois da incorporação do óleo de Vitis sp. (Figura 2), a formulação permanecesse estável. A incorporação de extratos vegetais a uma base para fins cosméticos, é uma prática que tem se tornado comum na área, pois conduz a alcançar a os efeitos terapêuticos da formulação (Silva et. al, 2019).

Após o preparo dos cremes das concentrações 1\%, 3\% e 5\%, foi observado que todas as incorporações foram visivelmente satisfatórias, pois não ocorreu alterações no aspecto, viscosidade, coloração e separação de fases (Figura 2). As concentrações de óleo de Vitis sp. foram escolhidas de acordo com as indicações de concentrações para dermocosméticos em geral, 1\% a 5\% (Revilla, 2001; Revilla, 2002). 
Figura 2: óleo obtido para o experimento.

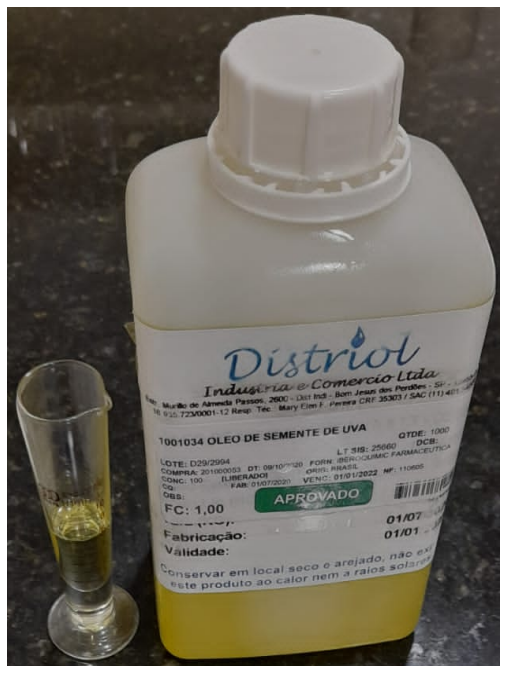

Fonte: Autores (2021).

Figura 3: Incorporação do óleo de Vitis sp., 1\%, 3\% e 5\%.

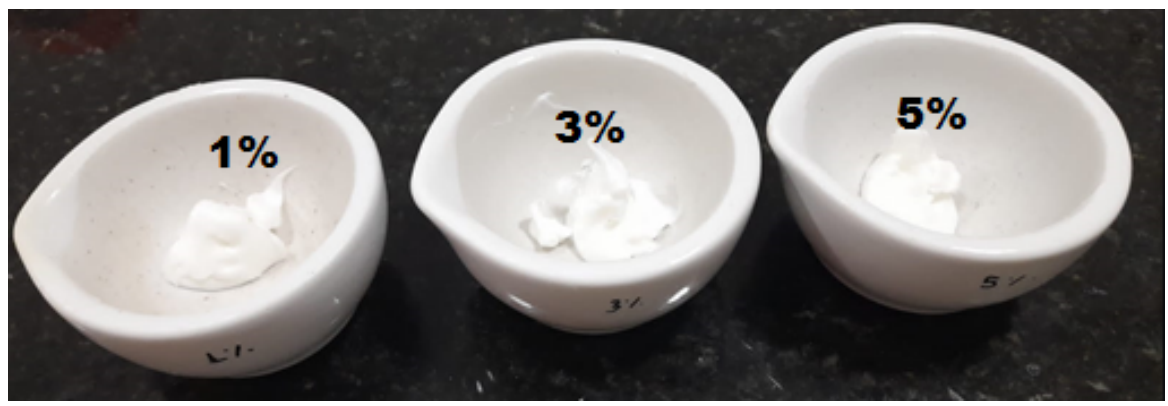

Fonte: Autores (2021).

As características macroscópicas foram observadas depois de 24 horas da formulação e após a avaliação de estabilidade acelerada. $\mathrm{O}$ estudo de estabilidade acelerada, permite a observação, em um curto intervalo de tempo, das variações causadas em diversos parâmetros (físico-químicos e microbiológicos) das formulações estudadas, quando submetidas a diversas condições de estresse, variando-se principalmente a temperatura de armazenamento, com o intuito de acelerar possíveis reações de degradação (Souza; Ferreira, 2010). Esses parâmetros foram avaliados de acordo com o Guia de Controle de Qualidade de Produtos Cosméticos (Quadro 2 e Tabelas 2 e 3). Os parâmetros macroscópicos mantiveram-se inalterados, de acordo com o Guia de Controle de Qualidade de Produtos Cosméticos (2008). Ambos os resultados, foram satisfatórios, não houve nenhuma mudança no aspecto, cor e odor (Tabela 1).

Quadro 2: Avaliação macroscópica das formulações após 24 horas de preparo.

\begin{tabular}{cccc}
\hline ANÁLISE & & CONCENTRAÇÃO (\%) & \\
\cline { 2 - 4 } & $\mathbf{1 \%}$ & $\mathbf{3 \%}$ & $\mathbf{5 \%}$ \\
\hline Cor & Branco & Branco & Branco \\
\hline Odor & Conforme & Conforme & Cremforme \\
\hline Aspecto & Creme & Creme &
\end{tabular}

Fonte: Autores (2021). 
Research, Society and Development, v. 10, n. 14, e08101421904, 2021

(CC BY 4.0) | ISSN 2525-3409 | DOI: http://dx.doi.org/10.33448/rsd-v10i14.21904

Tabela 1: Avaliação macroscópica após o estresse térmico (12 dias).

\begin{tabular}{cccc}
\hline ANÁLISE & \multicolumn{3}{c}{ CONCENTRAÇÃO (\%) } \\
\cline { 2 - 4 } & $\mathbf{1 \%}$ & $\mathbf{3 \%}$ & $\mathbf{5 \%}$ \\
\hline Cor & Branco & Branco & Branco \\
\hline Odor & Conforme & Conforme & Conforme \\
\hline Aspecto & Creme & Creme & Creme \\
\hline
\end{tabular}

Fonte: Autores (2021).

$\mathrm{O} \mathrm{pH}$ de qualquer cosmético, principalmente os cremes devem possuir uma faixa de $\mathrm{pH}$ compatível com a pele. Os cremes testados variaram entre 4,04 a 4,58, levando em conta os resultados do dia 1 e 12. A avaliação físico-química de pH e densidade foram realizadas no dia 1 e dia 12 , determinou os valores de $\mathrm{pH}$ e a densidade, calculou a média e desvio padrão (Tabelas 2 e 3). O desvio padrão assegura a confiabilidade dos resultados, pois quanto mais próximo do 0 mais correto é o resultado (Morettin; Bussab, 2010).

De acordo com Rodrigues, 1995, o pH da pele apresenta-se levemente ácido (4,6 - 5,8), o que favorece a proteção bactericida e fungicida em sua superfície. Ou seja, cosméticos a serem usados na pele, precisam não alterar significativamente esse $\mathrm{pH}$ para que não ocorra a perda da funcionalidade contra possíveis patógenos, logo o pH da formulação elaborada contempla essa faixa de pH, auxiliando não somente na atividade Anti-age mas também a proteção da pele.

Os valores do $\mathrm{pH}$ indicaram que em ambas as formulações houve uma leve diminuição do $\mathrm{pH}$ com o passar dos dias. Pode-se constatar que, as concentrações mais ácidas das formulações são decorrentes da elevação de temperatura, o que tende a acidificar facilmente e que quanto maior a concentração do óleo na emulsão em temperatura ambiente, maior o caráter ácido da formulação. A leve diminuição do $\mathrm{pH}$ das formulações pode ser decorrente da hidrólise dos ésteres de ácidos graxos presentes na formulação base, que geram ácidos graxos livres. Os ácidos graxos livres reduzem o pH das formulações pois atuam liberando prótons H+ para o meio (Souza; Ferreira, 2010). Pode-se sugerir que a eficácia do produto está garantida, já que o parâmetro analisado não apresentou alterações significativas entre as médias durante o teste de estabilidade acelerada. Uma variação brusca de pH indicaria que a formulação é instável e provavelmente está sofrendo degradação.

Tabela 2: Valores de $\mathrm{pH}$ antes e após o estresse térmico.

\begin{tabular}{ccc}
\hline Concentração (\%) & \multicolumn{2}{c}{ Determinação do valor do PH } \\
\cline { 2 - 3 } & pH (Dia 1) & pH (Dia 12) \\
\hline $1 \%$ & $4,04 \pm 0,01$ & $4,55 \pm 0,01$ \\
\hline $3 \%$ & $4,25 \pm 0,02$ & $4,56 \pm 0,14$ \\
\hline $5 \%$ & $4,28 \pm 0,12$ & $4,58 \pm 0,16$ \\
\hline
\end{tabular}

Fonte: Autores (2021).

A densidade é a razão entre massa e volume, essa característica indica o nível de hidratação do creme (Silva et. al, 2019). De acordo com os resultados das densidades, os cremes são altamente hidratantes e quanto menor a concentração maior é a densidade, em conta partida após o estresse térmico, no dia 12, as amostras apresentaram densidades menores que as iniciais. Nota-se que essa discreta diminuição pode ser explicada pelo fato da formulação ter ficado exposta a temperatura elevada, o que provavelmente favoreceu a evaporação em parte da parte aquosa, mas que não exerceu influência significativa na estabilidade de ambas formulações. 
Research, Society and Development, v. 10, n. 14, e08101421904, 2021

(CC BY 4.0) | ISSN 2525-3409 | DOI: http://dx.doi.org/10.33448/rsd-v10i14.21904

Tabela 3: Valores de densidade para análise das formulações contendo óleo de Vitis $s p$.

\begin{tabular}{ccc}
\hline Concentração (\%) & \multicolumn{2}{c}{ Determinação do valor da densidade } \\
\cline { 2 - 3 } & $\begin{array}{c}\text { Densidade (Dia 1) } \\
\text { (gml-1) }\end{array}$ & $\begin{array}{c}\text { Densidade (Dia 12) } \\
\text { (gml-1 ) }\end{array}$ \\
\hline $1 \%$ & $1,48 \pm 0,02$ & $1,46 \pm 0,12$ \\
\hline $3 \%$ & $1,49 \pm 0,01$ & $1,48 \pm 0,01$ \\
\hline $5 \%$ & $1,48 \pm 0,12$ & $1,49 \pm 0,15$ \\
\hline
\end{tabular}

Fonte: Autores (2021).

Apesar das pequenas variâncias de $\mathrm{pH}$ e densidade, estatisticamente não possuem relevância, porém indica o comportamento das emulsões, quanto a concentração do óleo e ao estresse térmico. O ensaio de centrifugação das formulações teve por objetivo verificar possíveis instabilidades, como: separação de fases, coalescência, entre outras, pelo aumento da mobilidade das partículas em consequência do aumento da força da gravidade. As formulações foram estáveis e não apresentaram nenhum dos fenômenos de instabilidade descritos. As amostras foram submetidas a centrifugação por 5 minutos e comparadas com os cremes antes do teste. Os resultados foram satisfatórios, uma vez que não ocorreu a separação de fases (Figuras 3 e 4).

Figura 4: Figura A representa o teste de centrifugação das formulações contendo o óleo de Vitis sp., onde todos foram estáveis. A Figura B demonstras que após 12 dias de estresse térmico a emulsão se manteve estável. Não apresentando nenhum sinal de instabilidade

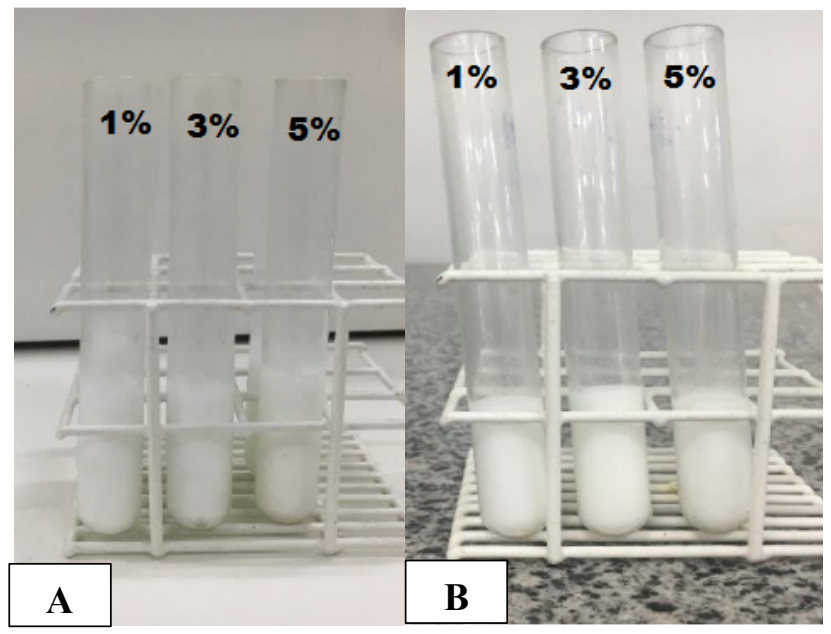

Fonte: Autores (2021).

O estresse térmico foi realizado e após 12 dias verificou que não houve sedimentação ou separação das fases (Figuras 3A e 3B), mantendo-se, portanto, estável as formulações.

Como nenhum dos parâmetros avaliados (propriedades organolépticas, $\mathrm{pH}$ e densidade) apresentou diferenças significativas, a formulação proposta foi aprovada nos testes de estabilidade acelerada, o que favorece num futuro projeto o desenvolvimento de uma segunda etapa desse trabalho que poderia ser investigação das atividades farmacológicas, a ampliação das avaliações da estabilidade acelerada e físico-químicas, bem como a avaliação das interações de seus constituintes com a pele e possíveis mecanismos de ação farmacológica da formulação come tempo de prateleira no desenvolvimento de um produto cosmético. 


\section{Conclusão}

A biodiversidade da flora brasileira nós confere uma posição estratégica na extração e produção de cosmecêuticos, pelas diversas propriedades terapêuticas de extratos presentes nas plantas nacionais. Assim, com a evolução e crescimento do mercado nacional e internacional, a pesquisa e desenvolvimento de biocosméticos torna-se primordial para a ampliação desse setor.

O controle de qualidade fornece informações sobre o comportamento do produto após submetido a testes que medem padrões físico-químicos e que simulam condições ambientais a que podem ser expostos, assim é possível saber se o produto está apto para o uso ou não, bem como o tempo de prateleira.

Os cremes desenvolvidos possuem compatibilidade entre o óleo e a formulação base, pois houve ausência de instabilidade, quando submetido aos testes de centrifugação e estresse térmico, e padrões de pH e densidade adequados.

As formulações acrescidas com óleo de Vitis sp. permaneceram estáveis aos testes de centrifugação e estresse térmico. A dispensabilidade das concentrações de óleo de Vitis $s p$. exercida na formulação foi satisfatória, pois não alterou a estabilidade da emulsão base, e atribuiu com um odor característico para emulsão.

A formulação elaborada é um produto interessante a ser produzido, devido a sua simplicidade, o que favorece uma possível segunda etapa dessa pesquisa, como a ampliação das avaliações de estabilidade e físico-químicas, avaliação microbiológica e investigação das atividades terapêuticas. Apesar da literatura dispor de informações sobre as atividades biológicas da Vitis sp, testes para investigação de atividades biológicas da formulação e perfil químico precisam ser feitos para maiores aprofundamentos do tema.

\section{Referências}

Amaral, K. F. V. \& Souza, R. B. A. (2019). A Importância da Hidratação Cutânea para melhor tratamento de Disfunções Estética. Revista Multidisciplinar e de Psicologia, 13(48), 763-771 https://doi.org/10.14295/idonline.v13i48.2284.

Atanasov, A. G. et al. (2015). Discovery and resupply of pharmacologically active plant-derived natural products: A review. Biotechnol. Advance, 33(8), 15821614, https://doi.org/10.1016/j.biotechadv.2015.08.001.

Brasil. Agência Nacional de Vigilância Sanitária. (2012). Formulário Nacional. (2a ed.), Anvisa.: https://www.gov.br/anvisa/pt-br/assuntos/farmacopeia/f ormulari o-nacional/arquivos/8065json-file- 1 .

BrasiL. Agência Nacional de Vigilância Sanitária. (2008). Guia de controle de qualidade de produtos cosméticos, Brasília: Anvisa, 130 p. file://C:/Users/gabriel.souza/Downloads/Guia\%20de\%20Controle\%20de\%20Qualidade\%20de\%20Produtos\%20Cosm\%C3\%A9ticos.pdf.

Brasil Anvisa. Agência Nacional de Vigilância Sanitária. (2004). Séries temáticas, cosméticos. Guia de estabilidade de produtos cosméticos.v.1. file://C:/Users/gabriel.souza/Downloads/guia-de-estabilidade-de-cosmeticos\%20(1).pdf..

Epamig, R. (2007). Caracterização fitoquímica e biológica de extratos obtidos de bagaço de uva (Vitis vinífera) e das variedades Merlot e Syrah, Dissertação (Mestrado em alimentos) - Faculdade de Engenharia de Alimentos. UFSC, Florianópolis. 211 f. https://repositorio.ufsc.br/xmlui/handle/123456789/94200?show=full.

Moraes, A. L. L. (2019). Desenvolvimento de formulação hidratante vegana contendo extratos de Calendula officinalis e Matricaria chamomilla. UFSC, Trabalho de conclusão de curso. https://repositorio.ufsc.br/handle/123456789/202101?show=full.

Morrettin, P. A. \& Bussab, W. O. (2010), Medidas-resumo. In: Morretin, P. A. Estatística Básica. (6a ed.), Editora Saraiva, 38-39.

Newman, D. J. \& Cragg, G. M. (2016). Natural Products as Sources of New Drugs from 1981 to 2014. Journal of Natural Products, 79: 629-661. https://pubs.acs.org/doi/10.1021/acs.jnatprod.5b01055 .

Revilla, J. (2002), Apontamentos para a Cosmética Amazônica. (2a ed.), INPA, Sebrae, 2002. 267-268.

Revilla, J. (20020. Plantas da Amazônia: oportunidades econômicas e sustentáveis. (2a ed.), SEBRAE: INPA, 2001. $143-145$.

Rodrigues L. (1995). A avaliação biofísica da superfície cutânea: indicadores fisiológicos da funcionalidade epidérmica. Revista Portuguesa de Farmácia, 45 (1): 52-9.

Rodrigues, A. M., Soares Junior, R. G., \& Souza, G. O. de. (2021). Evaluation of the chemical and biological profile of Hylocereus polyrhizus fruits. Research, Society and Development, [S. l.], v. 10, n. 9, p. e47110918290, 2021. 10.33448/rsd-v10i9.18290. https://rsdjournal.org/index.php/rsd/article/view/18290 .

Silva, F. V. F., Santos, M. C., Neiva, L. D. B. et al. (2019). Desenvolvimento e controle de qualidade de um gelcreme antiacneico a base de óleo de Copaífera officinalis L. (copaíba), Revista Eletrônica Acervo Saúde, 30. https://doi.org/10.25248/reas.e974.2019. 
Research, Society and Development, v. 10, n. 14, e08101421904, 2021

(CC BY 4.0) | ISSN 2525-3409 | DOI: http://dx.doi.org/10.33448/rsd-v10i14.21904

Silva, R. M. P. da, Simões, M. O. da S., \& Lins, A. C. (2021). Oxidative stress associated with physical exercise practice with active videogame: Nutritional supplementation as an antioxidant fator, Research, Society and Development, 10(5), e31910514986, 10.33448/rsd-v10i5.14986. https://rsdjournal.org/index.php/rsd/article/view/14986.

Souza, V. B. \& Ferreira, J. R. N. (2010). Desenvolvimento e estudos de estabilidade de cremes e géis contendo sementes e extratos do bagaço da uva Isabel (Vitis labrusca l.). Revista de Ciências Farmacêuticas Básica e Aplicada, 31(3). 217-222. https://rcfba.fcfar.unesp.br/index.php/ojs/article/view/368. 